\title{
Is Access Sheath Essential for Safety and Effective Retrograde Intrarenal Stone Surgery?
}

\author{
Yasin Yitgin ${ }^{1}$, Emine Yitgin ${ }^{2}$, Samed Verep ${ }^{3}$, Kamranbay Gasimov $^{3}$, Tzevat Tefik ${ }^{3}$ and Ayhan Karakose ${ }^{1}$ \\ ${ }^{1}$ Department of Urology, Faculty of Medicine, Istinye University, Istanbul, Turkey \\ ${ }^{2}$ Department of Anesthesiology, Faculty of Medicine, Istinye University, Istanbul, Turkey \\ ${ }^{3}$ Department of Urology, Istanbul Medical Faculty, Istanbul University, Istanbul, Turkey
}

\begin{abstract}
Objective: To evaluate the results of retrograde intrarenal surgery (RIRS) with flexible ureteroscope (f-URS), using ureteral access sheath and without the sheath.

Study Design: Descriptive study.

Place and Duration of the Study: Kesan State Hospital, Edirne, Turkey, between February 2019 and May 2020.

Methodology: Patients treated with RIRS for renal and proximal ureteral stone were evaluated. Two groups were formed that used ureteral access sheath or not. Operation and fluoroscopy times, postoperative complications and stone-free rates were compared.

Results: Group 1 consisted of 51 patients were operated with, using ureteral access sheath; and Group 2 having 62 patients, were operated without using ureteral access sheath. The mean volume of the stones was $1135 \mathrm{~mm}^{3}\left(73-7491 \mathrm{~mm}^{3}\right)$ in the group without access sheath and $1273 \mathrm{~mm}^{3}\left(251-3635 \mathrm{~mm}^{3}\right)$ in the group with access sheath. The mean operation time was 55 minutes (20-115 $\mathrm{min}$ ) in the group without access sheath, and 70 minutes (30-125 $\mathrm{min}$ ) in the group with access sheath. Postoperative febrile UTI was found in $5(8 \%)$ of the patients without access sheath, and in $4(8 \%)$ of the patients with access sheath $(p=0.733)$. The stone-free rate of the patients with radiological controls was 58 (93\%) in the group without access sheath and 46 (90\%) in the group with access sheath $(p=0.306)$. Fluoroscopy timings were 2.7 seconds $(0-8 \mathrm{sec})$ in the group without access sheath and 8.4 seconds $(2-20$ sec) in the group with access sheath $(p=0.001)$.

Conclusion: UAS usage has no marked impact on SFR, complication rate and operation time. RIRS can be performed safely and effectively without using UAS.
\end{abstract}

Key Words: Flexible ureteroscope, ITO score, Ureteral access sheath, Intrarenal stones.

How to cite this article: Yitgin Y, Yitgin E, Verep S, Gasimov K, Tefik T, Karakose A. Is Access Sheath Essential for Safety and Effective Retrograde Intrarenal Stone Surgery?. J Coll Physicians Surg Pak 2021; 31(10):1202-1206.

\section{INTRODUCTION}

Nephrolithiasis is a highly prevalent disease worldwide with rates ranging from $7-13 \%$ in North America, 5 - 9\% in Europe, and $1-5 \%$ in Asia. ${ }^{1}$ The prevalence of stone disease had been reported to be $14.8 \%$ in Turkey. ${ }^{2}$

With improvements in technology, endoscopic retrograde renal surgery (RIRS), performed using flexible ureterorenoscopy (fURS), has gained popularity. Increased use of f-URS for kidney stone treatment has been facilitated by the improvements of new generation flexible ureteroscopes, allowing easier access to the urinary tract and the collecting system, with excellent visualisation. $^{3}$

Correspondence to: Dr. Yasin Yitgin, Department of Urology, Faculty of Medicine, Istinye University, Istanbul, Turkey

E-mail: yasinyitgin@hotmail.com

Received: May 18, 2021; Revised: September 01, 2021; Accepted: September 20, 2021

DOI: https://doi.org/10.29271/jcpsp.2021.10.1202
The use of a ureteral access sheath (UAS) for pyeloureteroscopy was first described in 1974. The development of UAS is among the most important advances in endoscopic management of the upper urinary tract. ${ }^{4} \mathrm{UASs}$ allow easy, multiple access to the upper urinary tract and, therefore, significantly facilitate URS. The use of UASs improves vision by establishing a continuous outflow, decreasing intrarenal pressure, and potentially reducing operating time. ${ }^{5,6}$ The UASs have the disadvantage of increasing cost and injury to the ureter. ${ }^{7}$ In a recent study with 359 patients aged 14-90 years, who underwent RIRS, it was found that usage of UAS provoked mild and serious ureteral injuries in $33 \%$ and $13 \%$ of the patients, respectively. ${ }^{8}$ Although it has been demonstrated that UAS usage has benefits, some studies reporting improvement in stone-free rate (SFR) in patients undergoing f-URS for upper urinary tract stone disease, ${ }^{9}$ others report an increased SFR ${ }^{6}$.

Some nomograms have developed to predictSFR after f-URS, in order to guide the selection of optimal treatment. ITO nomogram, which was determined five preoperative characteristics, stone volume and number, presence of lower pole calculi or hydronephrosis, and operators' experience of f-URS was one of them. ${ }^{10}$ 
The aim of this study was to compare cases with and without UAS for considering the possibility to continue without UAS in case ofinsertion UAS failure.

\section{METHODOLOGY}

Inthis descriptive study, 113 patients undergoingf-URSoperation at Kesan State Hospital, Edirne, Turkey, between February 2019 and May 2020 were included. Group 1, consisted of 51 patients, were operated with, using UAS; whereas, Group 2, consisted of 62 patients were operated without using UAS. In addition, according to stones location the authors formed three subgroups that were the proximal ureter, upper-middle pole, and lower pole, respectively; and analysed the comparative results between the groups. Approved written informed consent, properly explaining the surgical method, benefits and possible risks of surgical procedure, were read and filled in preoperatively by all of the patients included in the study. The study was approved by the Committee on Research Ethics at the institution in which the research was conducted. Indications for f-URS were kidney and proximal ureteral stones. All operations were performed by one expert urologist. Preoperative renal stone characteristics and presence of hydronephrosis were detected with computerised tomography. Demographic parameters (age, gender, smoking status), stone characteristics that are side, location (proximal ureter, upper and middle pole, lower pole), density (Hounsfield unit), volume $\left(\mathrm{mm}^{3}\right)$, intraoperative outcomes (operation time, fluoroscopy time, use of UAS), SFR, also ITO score from nomograms and, surgical complications (fever, urinary tract infection) were collected. Patients were checked with X-ray or CT for SFR in 10 days and three months, postoperatively. Residual fragments less than $2 \mathrm{~mm}$ were considered as stone-free. Preoperatively, all patients had sterile urine culture and all signed informed consent. Patients over 75 years of age and under 18 years of age, with concurrent distal or middle ureter stones, positive urine culture before surgery, and patients with solitary kidneys were excluded from the study.

Firstly, diagnostic ureteroscopy was performed under general anesthesia by ultrathin ureterorenoscope (4,5/6,5 Fr, Richard Wolf) to all patients in order to investigate the presence of other pathological conditions. The patients were divided into two groups (Group 1 with UAS and Group 2 without UAS). In both groups, procedure was started with placement of 0.035 inch PTFE guidewire up to the renal pelvis under fluoroscopic guidance and routinely using semi-rigid URS to reach UPJ for making ureteral dilatation; and it was repeated this procedure twice. After that, a 7.95 fr flexible ureterorenoscope (URF-P7, Olympus) was used for operations. A 10-12 fr hydrophilic UAS (Cook $\left.{ }^{\circledR}\right)$ was also used in Group 1. Flexible ureteroscope was proceeded up to the renal pelvis over PTFE guidewire in Group 2 as well as $8 f$ feeding catheter for bladder drainage. Litothripsy was performed with holmium laser using 272 and
365-Im fiber wtih dusting technique. A 4.8 fr jj stent was placed in all patients at the end of the operation. J stent was removed between 2-4 weeks postoperatively.

Statistical analysis was done using SPSS version 20.0. Continuous variables (comparing mean values) were analysed with student's t-test and one-way Anova, while Chi-square test was used for categorical variables. $\mathrm{P}<0.05$ was considered statistically significant.

\section{RESULTS}

The data of 113 patients were analysed, retrospectively. RIRS was performed in 51 (45\%) patients in Group 1 and 62 (55\%) patients in Group 2. The mean age of the patients was $44.9 \pm$ 15.1 (20-73) and 46.1 \pm 13 (20-74) years; while the male/female ratio was 32/19 and 33/29 in Group 1 and Group 2, respectively. The stones were localised in proximal ureter, upper-middle and lower pole in both groups, and their mean size was similar (Group 1: $1273 \mathrm{~mm}^{3}$ and Group 2: $1135 \mathrm{~mm}^{3}$ ). The two Groups did not show statistical differences in preoperative factors regarding age, gender, smoking, stone side-location-volume, $\mathrm{HU}$, hydronephrosis, and ITO scores; and the values are summarised in Table I.

Table I: Demographic and preoperative parameters of RIRS patients (with and without access sheath).

\begin{tabular}{|c|c|c|c|}
\hline & $\begin{array}{c}\text { Group } 1 \\
\text { Acces sheath (+) }\end{array}$ & $\begin{array}{c}\text { Group } 2 \\
\text { Access sheath (-) }\end{array}$ & $\mathbf{P}$ \\
\hline Patients, $\mathrm{n}$ & $51(45 \%)$ & $62(55 \%)$ & - \\
\hline Age (years) & $44.9 \pm 15.1(20-73)$ & $46.1 \pm 13(20-74)$ & 0.648 \\
\hline $\begin{array}{l}\text { Gender, } \\
\text { male/female }\end{array}$ & $32 / 19(63 \% / 37 \%)$ & $33 / 29(53 \% / 47 \%)$ & 0.308 \\
\hline Smoker/Non-smoker & $31 / 20(60 \% / 40 \%)$ & $36 / 26(58 \% / 42 \%)$ & 0.829 \\
\hline Stone side (R/L) & $28 / 23(55 \% / 44 \%)$ & $30 / 32(48 \% / 52 \%)$ & 0.421 \\
\hline $\begin{array}{l}\text { Stone location } \\
\text { (proximal ureter/ } \\
\text { upper-mid pole } \\
\text { /lower pole) }\end{array}$ & $\begin{array}{c}12 / 21 / 18 \\
(24 \% / 41 \% / 35 \%)\end{array}$ & $\begin{array}{c}22 / 24 / 16 \\
(35 \% / 39 \% / 26 \%)\end{array}$ & 0.133 \\
\hline $\begin{array}{l}\text { Stone volume } \\
\left(\mathrm{mm}^{3}\right)\end{array}$ & $1273 \pm 1036(251-3635)$ & $1135 \pm 1268(73-7491)$ & 0.538 \\
\hline Hydronephrosis & $41(80 \%)$ & $50(81 \%)$ & 0.973 \\
\hline Hounsfield units & $918 \pm 190(565-1275)$ & $919 \pm 222(356-1388)$ & 0.968 \\
\hline ITO scores & $15(3-23)$ & $16(3-23)$ & 0.493 \\
\hline
\end{tabular}

Table II: Comparison of operative parameters of RIRS patients (with and withoutaccess sheath).

\begin{tabular}{|l|c|c|c|}
\hline & $\begin{array}{c}\text { Group 1 } \\
\text { Acces sheath (+) }\end{array}$ & $\begin{array}{c}\text { Group 2 } \\
\text { Access sheath (-) }\end{array}$ & P \\
\hline Stone-free rates & $46(90 \%)$ & $58(93 \%)$ & 0.306 \\
\hline Postoperative UTI & $4(8 \%)$ & $5(8 \%)$ & 0.733 \\
\hline $\begin{array}{l}\text { Operation time } \\
\text { (minute) }\end{array}$ & $\begin{array}{c}70.87 \pm 28.09 \\
(30-125)\end{array}$ & $\begin{array}{c}55.39 \pm 20.68 \\
(20-115)\end{array}$ & 0.001 \\
\hline $\begin{array}{l}\text { Flouroscopy time } \\
\text { (second) }\end{array}$ & $\begin{array}{c}8.47 \pm 4.35 \\
(2-20)\end{array}$ & $\begin{array}{c}2.70 \pm 1.70 \\
(0-8)\end{array}$ & 0.001 \\
\hline
\end{tabular}

Stone-free rates in Group 1 and Group 2 were 46 (90\%) and 58 (93\%), respectively. Postoperative UTI was detected in 4 patients in Group 1 and 5 patients in Group 2. The authors observed no significant difference between the two groups in terms of stone-free rates and postoperative UTI. 


Table III: Comparison of preoperative and postoperative parameters according to stone location.
\begin{tabular}{|l|l|l|l|l|}
\hline & Proximal ureter & Upper-mid pole & Lower pole & P \\
\hline Operation time & $47.24+/-20.07$ & $70.12+/-26.30$ & $67.38+/-21.19$ & $<0.001$ \\
\hline Flouroscopy time & $3.17+/-2.89$ & $5.92+/-4.60$ & $6.76+/-4.21$ & $<0.001$ \\
\hline Stone volume $\left(\mathrm{mm}^{3}\right)$ & $576(73-2098)$ & $1482(125-7491)$ & $1493(283-4296)$ & $<0.001$ \\
\hline Stone-free rates & $33(97 \%)$ & $44(98 \%)$ & $27(80 \%)$ & $* * * 0.003$ \\
\hline Postoperative UTI & $3(8 \%)$ & $4(9 \%)$ & $2(6 \%)$ & 0.894 \\
\hline Hounsfield U. & $807(356-1147)$ & $970(618-1388)$ & $972(708-1190)$ & $* * .018$ \\
\hline ITO scores & $19(8-23)$ & $16(8-23)$ & $10(3-20)$ & $* * *<0.001$ \\
\hline Hydronephrosis & $34(100 \%)$ & $17(50 \%)$ & $* * * * *<0.001$ \\
\hline $\begin{array}{l}* \text { Proximal ureter group showed significant shorter operation and flouroscopy time. ** Stones in proximal ureter group were smaller and soft than others. *** Lower } \\
\text { pole stone surgery showed more rest ratio. ****ITO scores were different in all three groups. *****Hydronephrosis was statistically less in lower pole group. }\end{array}$
\end{tabular}

The mean operation time were $70.87 \pm 28.09$ minutes in Group 1 and $55.39 \pm 20.68$ in Group 2, respectively. Flouroscopy times were $8.47 \pm 4.35$ seconds in Group 1 and $2.70 \pm$ 1.70 in Group 2. Both were significantly lower in Group 2 (Table II).

Pre- and postoperative comparative parameters of stones in different locations are shown in Table III. Operation and fluoroscopy times for proximal ureter, upper-mid pole and pelvis, lower pole stones were 47.24 $\pm 20.07,70.12 \pm$ $26.30,67.38 \pm 21.19$ minutes and $3.17 \pm 2.89,5.92 \pm 4.60$, $6.76 \pm 4.21$ minutes, respectively. Both parameters were statistically shorter in proximal ureter group. Clinically significant residual fragments were detected in 6 of 15 lower pole stone patients, which was significantly different from other groups. Stone volume and Hounsfield unit were significantly lower in the proximal ureter group. ITO scores were different in all three groups. Hydronephrosis and SFR were less in lower pole group and was statistical difference. There was no difference in postoperative urinary tract infection parameter in all three groups.

\section{DISCUSSION}

The first f-URS was used in 1964 by Marshall, and the use of $\mathrm{f}$-URS in the treatment of upper urinary tract stones began in $1980 \mathrm{~s} .{ }^{4}$ Recently, f-URS has gained popularity in the treatment of kidney stones with the widespread use of laser and technical developments in new devices. ${ }^{11,12}$

Equipment was required for f-URS devices to reach the upper urinary system. For this reason, guide-tube method was firstly applied in $1974 .{ }^{4}$ Nowadays, UAS is preferred in upper system stone treatment because it provides easier and multiple passages, better vision and fluid circulation with technological developments. On the other hand, the disadvantages that may result in ureteral injury and stenosis after the use of UAS have been shown. ${ }^{13}$ European Association of Urology (EAU) Urolithiasis guidelines recommends that UAS can be used according to surgeon's preference. ${ }^{11}$ In addition, evidences describe UAS advantages like SFR results are very limited. Researchers advocating the use of UAS state that it can increase the irrigation flow and thus stone fragments can be cleaned more easily with basketing. ${ }^{5,6}$ This situation was not supported by the findings of the authors. In this study, the authors used dusting tech- nique fragmenting the stones into tiny pieces $<1 \mathrm{~mm}$ and not used any instrument such as basket catheter to remove stone fragments. However, there was no significant difference between the two Groups in terms of SFR rates in this study.

The authors mentioned that using UAS in RIRS had not increased the complication rates at recent studies. ${ }^{14,15}$ When the studies about the UAS usage were evaluated, Berquet et al. stated that the use of UAS did not change SFR. Traxer et al. reported that SFR was higher in patients not using UAS, but there was no significant difference in regression analysis. In the recent study, the authors found that the SFR is higher in patients without UAS. However, the authors stated that the stone size was smaller in the group without UAS. Berquet et al. found the operation time was shorter in the group without UAS but there was no statistical difference. Traxer et al. and Lima et al. stated that the operation time was shorter, and the result was statistically significant., ${ }^{9,16,17}$ In the present study, there was no difference between the two Groups in terms of stone volume, location, HUs and ITO scores. Moreover, there was no significant difference in SFR in the recent study. No difference in terms of SFR between the two Groups may be due to surgeon's experience, operation technique performed with dusting and the ureteral JJ stent placement following the procedure. The operation time was found significantly less in the non-UAS group. The reasons for this may be the inclusion of the time spent during UAS insertion and the need to return to the UAS with f-URS during initial insertion of the laser probe. Therefore, when UAS is not used, repeated entry and re-entry into the collecting system is not performed, and the surgeon completed the procedure with a single entry. Moreover, stone samples can be taken at the end of the operation. In addition, the authors assess that, in RIRS operations without using UAS, there is no deterioration in image quality during operation and it does not cause any disadvantage in terms of time-length with the improvements in f-URS technology. Moreover, according to this study, if UAS is not used, patients and the surgical team are exposed to less radiation.

With the use of UAS, it may cause ureteral ischemia due to decreased blood flow in the ureter. The histopathological effect of the use of UAS in pig ureter was investigated. After 30 and 60 minutes of UAS usage, the ureters were examined histologically immediately, first and second weeks after the 
procedure. While acute inflammation findings were observed in the immediate dissection ureter, minimal transmural inflammation was observed in the ureter dissected after 2 weeks. ${ }^{18}$ In this study, it was seen that UAS usage does not cause any severe damage on the ureter, clinically. However, apart from histopathological effect, there may also be lacerations in the ureteric layers during the movement of UAS in the ureter. Traxer et al. stated that the ureteral wall injury rate was $46.5 \%$ in their study, which examined 359 patients undergoing RIRS with 12/14 Fr UAS. Additionally, serious ureteral wall injury was detected in $13.3 \%$ of patients. They also reported that ureteral injury rate significantly decreased in patients placed JJ-stents before RIRS. ${ }^{8}$ Lildal et al. compared RIRS patients with UAS used $(10 / 12 \mathrm{Fr})$ and unused, they found that ureteral injury rate was higher in patients with UAS usage (50\% vs. 36\%). ${ }^{19}$ There was no difference in terms of complications between UAS and non-UAS groups in this study. However, some trials demonstrated that UAS can be responsible for per- and postoperative complications, such as ureteral wall perforation, mucosal injury, urinary extravasa-

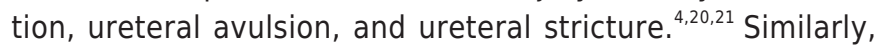
Lallas et al. demonstrated that UAS was associated with a transient decrease in ureteral blood flow, which could potentially lead to further ureteral stricture. ${ }^{22}$

Physiological intrarenal pressure, which is between 5 and 10 $\mathrm{cm} \mathrm{H}_{2} \mathrm{O}$ and may increase during endoscopic surgery is significant for postoperative complications such as bleeding, perirenal collection, and sepsis. Studies have reported that 40 $\mathrm{cm} \mathrm{H}_{2} \mathrm{O}$ is the safe upper limit for this pressure. ${ }^{23,24}$ It has been shown that irrigation levels can be increased up to $35-80 \%$ and intrarenal pressure can be kept below $30 \mathrm{~cm} \mathrm{H}_{2} \mathrm{O}$ when ureteral access sheath is used. ${ }^{25}$ Significant complications which could occure by high intrarenal pressure in both groups were not observed thanks to our using of low irrigation pressure.

There are some limitations in this study. First, this is a study from a single centre with a relatively small population. Second, the choice of using a UAS is left at the surgeon's discretion so there might be some selection biases even if there was no difference in terms of stone characteristics, demographic data of patients between two groups. Third, as the patients did not have long-term follow-up, the data about late complications such as ureteral stenosis could not be collected yet.

\section{CONCLUSION}

There is no remarkable differences between using UAS or not, with complication and succes rate in RIRS. RIRS can be performed safety and effectively without using UAS. Not using UAS in RIRS can be performed safely without reducing success and increasing complication rates. Further studies would support the outcomes of this study.

\section{ETHICAL APPROVAL:}

The study was approved by the Ethics Committee of Kesan State Hospital, Edirne, Turkey.

\section{PATIENTS' CONSENT:}

Patients' informed consents were obtained for publication of the case data.

\section{CONFLICT OF INTEREST:}

The authors declared no conflict of interest.

\section{AUTHORS' CONTRIBUTION:}

YY: Conception or design of the work; or the acquisition, analysis, or interpretation of data for the work. Final approval of the version to be published. Agreement to be accountable for all aspects of the work.

EY: Data collection, data analysis, result, discussion and literature review.

SV, KG: Results and literature review.

$\Pi$ T: Discussion and literature review.

AK: Drafting the work or revising it critically for important intellectual content.

\section{REFERENCES}

1. Sorokin I, Mamoulakis C, Miyazawa K, Rodgers A, Talati J, Lotan Y. Epidemiology of stone disease across the world. World J Urol 2017; 35(9):1301-20. doi: 10.1007/ s00345-017-2008-6.

2. Tefekli A, Tok A, Altundere F, Barut M, Berberoglu Y, Müslümanoglu AY. Lifestyle and nutritional habits in urinary stone patients. Turk J Urol 2005; 31:113-8.

3. Türk C, Petř́k A, Sarica K, Seitz C, Skolarikos A, Straub M, et al. EAU guidelines on interventional treatment for urolithiasis. Eur Urol 2016; 69(3):475-82. doi: 10.1016/j. eururo. 2015.07.041.

4. Yitgin Y, Karakose A, Akdeniz E. Our experience of retrograde intrarenal surgery in the treatment of upper urinary tract stones. Endourol Bull 2021; 13(1):23-8.

5. Stern JM, Yiee J, Park S. Safety and efficacy of ureteral access sheaths. J Endourol 2007; 21(2):119-23. doi: 10.1089/end.2007.9997.

6. L'esperance JO, Ekeruo WO, Scales CD, Marguet CG, Springhart WP, Maloney ME, et al. Effect of ureteral access sheath on stone-free rates in patients undergoing ureteroscopic management of renal calculi. Urology 2005; 66(2):252-5. doi: 10.1016/j.urology.2005.03.019.

7. Al-Qahtani SM, Letendre J, Thomas A, Natalin R, Saussez T, Traxer $O$. Which ureteral access sheath is compatible with your flexible ureteroscope? J Endourol 2014; 28(3):286-90. doi: 10.1089/end.2013.0375.

8. Traxer O, Thomas A. Prospective evaluation and classification of ureteral wall injuries resulting from insertion of a ureteral Access sheath during retrograde intrarenal surgery. J Urol 2013; 189(2):580-4. doi: 10.1016/j.juro.2012.08.197.

9. Berquet G, Prunel P, Verhoest G, Mathieu R, Bensalah K. The use of a ureteral Access sheath does not improve stone-free rate after ureteroscopy for upper urinary tract stones. World J Urol 2014; 32(1):229-32. doi: 10.1007/s00345-013- 
1181-5.

10. Ito H, Sakamaki K, Kawahara $\mathrm{I}$, Terao $\underline{\mathrm{H}}$, Yasuda $\mathrm{K}$, Kuroda $\underline{\mathrm{S}}$, et al. Development and internal validation of a nomogram for predicting stone-free status after flexible ureteroscopy for renal stones. BJU Int 2015; 115(3):446-51. doi: 10.1111/bju.12775.

11. EAU Guidelines. Edn. Presented at the EAU Annual Congress Amsterdam 2020. ISBN 978-94-92671-07-3.

12. Tefekli A, Cezayirli F. The history of urinary stones: In parallel with civilisation. Scientific World J 2013; 2013: 423964. doi: 10.1155/2013/423964.

13. Kaplan A, Lipkin ME, Scales CD, Preminger GM. Use of ureteral access sheaths in ureteroscopy. Nat Rev Urol 2016; 13(3):135-40. doi: 10.1038/nrurol.2015.271.

14. Alhunaidi O, Ahmad AA, EL-Nahas AR, Akroof B, Alamiri A, Al-Ajrawi $F$, et al. Impact of case volume per year on flexible Ureteroscopy practice: An internet based survey. BMC Urol 2019; 19(1):134. doi: 10.1186/s12894-019-0568-z.

15. Zilberman DE, Lazarovich A, Winkler H, Kleinmann N. Practice patterns of ureteral access sheath during ureteroscopy for nephrolithiasis: A survey among endourologists worldwide. BMC Urol 2019; 19(1):58. doi: 10.1186/s12894019-0489-x.

16. Traxer O, Wendt-Nordahl G, Sodha H, Rassweiler J, Meretyk $\mathrm{S}$, Tefekli A, et al. Differences in renal stone treatment and outcomes for patients treated either with or without the support of a ureteral access sheath: The clinical research office of the endourological society ureteroscopy global study. World J Urol 2015; 33(12):2137-44. doi: 10.1007/ s00345-015-1582-8.

17. Lima A, Reeves T, Geraghty R, Pietropaolo A, Whitehurst L, Somani BK. Impact of ureteral access sheath on renal stone treatment: Prospective comparative non-randomised outcomes over a 7-year period. World J Urol 2020; 38(5):1329-33. doi: 10.1007/s00345-019-02878-5.
18. Özsoy M, Kyriazis I, Vrettos T, Kotsiris D, Ntasiotis P, Seitz C, et al. Histological changes caused by the prolonged placement of ureteral access sheaths: An experimental study in porcine model. Urolithiasis 2018; 46(4):397-404. doi: 10.1007/s00240-017-1007-9.

19. Lildal SK, Andreassen KH, Jung H, Pedersen MR, Osther PJS. Evaluation of ureteral lesions in ureterorenoscopy: Impact of access sheath use. Scand J Urol 2018; 52(2):157-61. doi: 10.1080/21681805.2018.1430705.

20. Abrahams HM, Stoller ML. The argument against the routine use of ureteral access sheaths. Urol Clin North Am 2004; 31(1):83-7. doi: 10.1016/S0094-0143(03)00085-5.

21. Karakose A, Aydogdu O, Atesci YZ. The use of the amplatz sheath in percutaneous nephrolithotomy: Does amplatz sheath size matter? Curr Urol 2013; 7(3):127-31. doi: $10.1159 / 000356264$.

22. Lallas CD, Auge BK, Raj GV, Santa-Cruz R, Madden JF, Preminger GM. Laser Doppler flowmetric determination of ureteral blood flow after ureteral access sheath placement. J Endourol 2002; 16(8):583-90. doi: 10.1089/089277 902320913288.

23. Sener TE, Cloutier J, Villa L, Marson F, Butticè S, Doizi S, et al. Can we provide low intrarenal pressures with good irrigation flow by decreasing the size of ureteral access sheaths? J Endourol 2016; 30(1):49-55. doi: 10.1089/end.2015. 0387.

24. Karakose A, Yüksel MB. An extremely rare complication of double-j stenting: Renal parenchymal perforation with no hematoma. Curr Urol 2011; 5(3):165-8. doi.org/10. 1159/000327472.

25. Rehman J, Monga M, Landman J, Lee DI, Felfela T, Conradie $\mathrm{MC}$, et al. Characterisation of intrapelvic pressure during ureteropyeloscopy with ureteral access sheaths. Urology 2003; 61(4):713-8. doi: 10.1016/s0090-4295(02)02440-8. 